\title{
Review
}

\section{The Generally Recognized as Safe (GRAS) Process for Industrial Microbial Enzymes}

\author{
Vincent Sewalt, ${ }_{1}^{1,2}$ Diane Shanahan, ${ }^{1,3}$ Lori Gregg, ${ }^{1,4}$ \\ James La Marta, ${ }^{1,5}$ and Roberto Carrillo, \\ ${ }^{1}$ Enzyme Technical Association, Washington, DC \\ ${ }^{2}$ DuPont Industrial Biosciences, Palo Alto, CA \\ ${ }^{3}$ BASF Corp., San Diego, CA \\ ${ }^{4}$ Novozymes North America, Inc., Franklinton, NC \\ ${ }^{5}$ DSM Nutritional Products, LLC, Parsippany, NJ \\ ${ }^{6}$ Enmex, Tlalnepantla, Mexico
}

\begin{abstract}
The Generally Recognized as Safe (GRAS) process is well suited for enzymes, given the general availability of scientific data supporting enzyme safety, and the generally recognized (peer-reviewed) methodology and decision trees for evaluating the safety of microbial enzymes used in food processing and in animal feed, respectively. In this paper we describe the elements of a safety evaluation of an enzyme used in food and feed and how the available published data and information related to each element can form the basis for a determination of GRAS for an intended use.
\end{abstract}

Keywords: GRAS, microbial enzymes, safe strain lineage, history of safe use, safety evaluation, food and feed

\section{Introduction}

he concept of Generally Recognized as Safe (GRAS) as a basis for US regulatory compliance is provided in the Federal Food, Drug, and Cosmetic Act (FDCA) by means of the Food Additive amendment of 1958. Any substance that is reasonably expected to become a component of food, or is otherwise affecting the characteristics of food, is a food additive. Food additives are subject to premarket approval by the U.S. Food and Drug Administration (FDA), unless the substance is GRAS among experts qualified by scientific training and experience to evaluate the safety of the substance in the intended use. The GRAS determination relies on the safety of the substance to be adequately shown through scientific procedures, or through experience based on common use in food prior to 1958, under the conditions of its intended use. 'General recognition" and "qualified expert" are key components of this statutory language. A determination that a substance is GRAS requires both technical evidence of safety and a basis to conclude that the technical evidence of safety is generally known and accepted. The data and information relied on to establish safety must be generally available, and there must be consensus among qualified experts about the safety of the substance for the intended use. Under the law, a substance that is GRAS for a particular use may be marketed for that use without the agency's review and approval that is normally required for a new food additive as defined in definition (s) of 21 U.S.C. $\S 321 .^{1}$

Following the passage of the Food Additive Amendment of FDCA in 1958, FDA published a list of GRAS ingredientsnow codified in Title 21 of the Code of Federal Regulations Part 182 - and in 1972 created, by regulation, a GRAS affirmation process that allowed industry to petition the agency to make a GRAS determination. ${ }^{2,3}$ Because the GRAS affirmation process became overly burdensome from an administrative point of view, in 1997 FDA published a Proposed GRAS Notice Rule. ${ }^{4}$ The rule outlines a process that allows a firm to submit a GRAS Notice to the Agency and, upon review, FDA will publicly list its response via a letter. FDA's Center for Food Safety and Applied Nutrition (CFSAN) has posted the full list of GRAS Notices it has received on its website. This list maintained by CFSAN is referred to as the GRAS Notice Inventory. ${ }^{5}$ The inventory of GRAS notices provides information about GRAS Notices filed since 1998, when FDA received its first GRAS notice. Once FDA responds to a GRAS Notice, the text of FDA's response letter is also available as part of the record for that notice. FDA updates this information periodically throughout the year. Over 600 GRAS Notices have been filed with CFSAN through 2015, of which approximately $14 \%$ are related to food enzymes. Figure 1 indicates the number of GRAS Notifications processed and the number that received a "No Questions" response letter. As displayed by the graph, food enzyme GRAS Notices meet the GRAS criteria consistently and result in very few findings that the notifier's GRAS determinations were unsubstantiated by FDA or withdrawn by the notifier.

While the 1997 Proposed Rule addressed GRAS Notification for both human and animal food, the review of GRAS Notices was not implemented by FDA's Center for Veterinary Medicine

(C) Vincent Sewalt, et al., 2016; Published by Mary Ann Liebert, Inc. This Open Access article is distributed under the terms of the Creative Commons License (http://creativecommons.org/licenses/by/4.0), which permits unrestricted use, distribution, and reproduction in any medium, provided the original work is properly credited. 


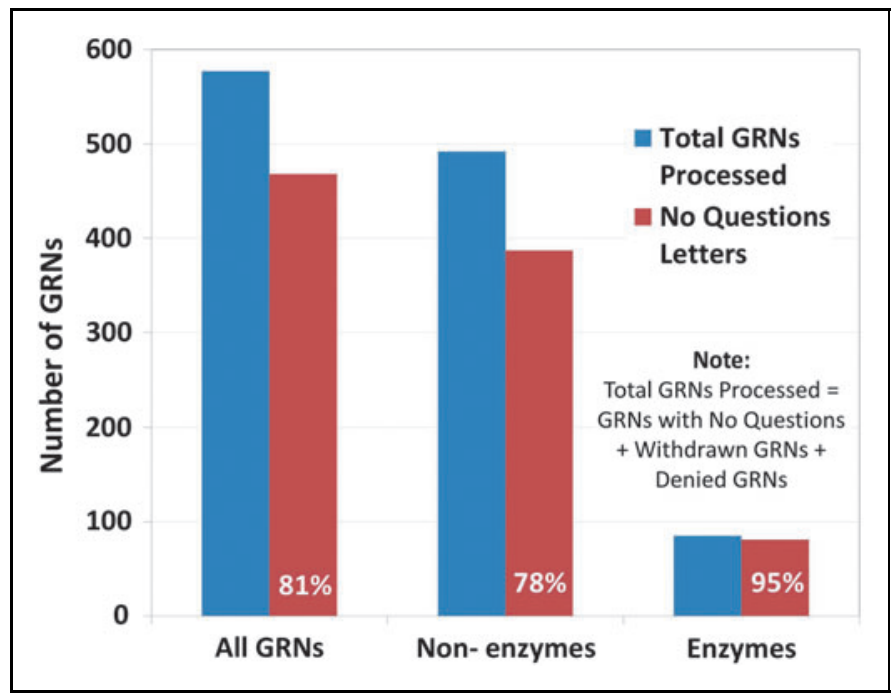

Fig. 1. GRAS Notices processed by CFSAN from 1997 through 2015. GRAS, Generally Recognized as Safe; CFSAN, Center for Food Safety and Applied Nutrition; GRN, GRAS Notice

(CVM) as accepted practice for animal food until June 4, 2010, when FDA/CVM published the Notice of Pilot Program for Substances Generally Recognized as Safe Added to Food for Animals. ${ }^{6}$ The CVM GRAS Notification Program, at this time, is the subject of some different interpretations, is not identical to that of CFSAN, and leaves much more room for discretionary requirements by CVM. ${ }^{7}$ To date, only 7 of 20 GRAS Notices appear on CVM's publicly available GRAS Notice Inventory list with a No Questions response letter, two of which are for enzymes.

The GRAS process is well suited for enzymes, given the general availability of scientific data supporting enzyme safety, and the generally recognized (peer-reviewed) methodology and decision trees for evaluating the safety of microbial enzymes used in food processing and in animal feed, respectively. ${ }^{8-11}$ The impact of feed enzymes on human food safety is generally not of immediate concern, as humans consuming products from the target animal are not exposed to the enzyme. The publicly available methods for evaluating the safety of food components derived from genetically modified organisms are also very relevant. ${ }^{12-18}$ These published methods provide rigorous guidelines and a framework for the safety evaluation of microbial enzymes used in food.

The safety evaluation methodology in the above published references addresses the safety of the genetic transformation materials and methods, the safety of the newly introduced enzyme in its intended use, and the safety of the production host. The manufacturing process for enzyme preparations is quite standardized in the enzyme industry and usually consists of submerged fermentation of pure cultures followed by inactivation of the production organism, enzyme recovery steps, and final formulation. ${ }^{19-21}$ Consideration of dietary exposure is also an essential piece of the assessment. As enzymes may be used in multiple food manufacturing processes or in multiple animal feed sources, the highest consumption by humans/animals is used in the safety calculations. Generally, rodent data are used to

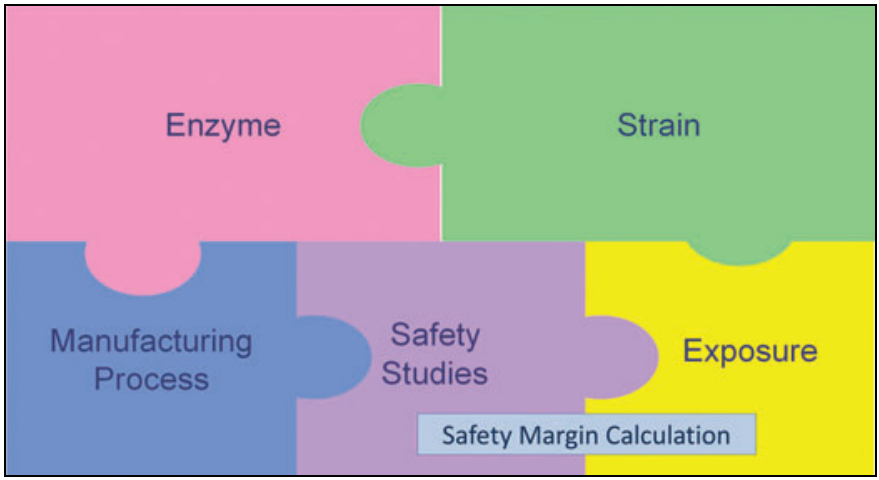

Fig. 2. Elements of a safety evaluation for food/feed enzymes. The Safety Margin is calculated from the exposure estimate in the intended use(s) and the No Observed Adverse Effect Level from an applicable oral toxicity study.

support the safety in humans, pigs, and poultry, with the requirement that the margin of safety be at least $100 .^{9,10,22} \mathrm{Al}-$ ternatively, animal feed safety can be supported with target animal safety studies.

When making a GRAS determination for an enzyme preparation, members of the Enzyme Technical Association (Washington, DC) follow publicly available guidelines and methodology for evaluating the safety of microbial enzyme preparations used in food and feed. ${ }^{9-11}$ As shown in Fig. 2, there are five main elements that must be considered when conducting a safety evaluation of microbial food enzymes: the enzyme; the production strain; the manufacturing process; safety studies; and estimation of dietary exposure and calculation of resulting safety margin.

In this paper we describe the elements of a safety evaluation of an enzyme used in food and feed and how the available published data and information related to each element can form the basis for a determination of GRAS for an intended use. A GRAS Notice to FDA for enzymes starts with a GRAS exemption claim (described on FDA's website in guidance on How to Submit a GRAS Notice) and includes additional information about the enzyme's identity, source of the enzyme (description of the production organism), method of manufacture, technical use/application, safety studies, and estimation of human exposure as described in FDA/CFSAN guidance on enzymes. ${ }^{23}$ The information required is described in more detail below.

\section{General Use and Safety of Enzymes}

Enzymes are proteinaceous molecules with a globular structure produced by all living cells in order to perform the biochemical reactions required to support life. They act as selective catalysts that accelerate metabolic processes. Enzymes are effective in small amounts and increase the speed of a reaction by providing an alternative reaction pathway of lower activation energy. As a result, products are formed faster and reactions reach their equilibrium state more rapidly. Enzymes operate within a narrow set of conditions, such as temperature and $\mathrm{pH}$ (acidity), and are subject to inhibition by various means. Enzymes serve a wide variety of functions inside living organisms, from ripening of fruits to breaking down food in the stomachs of 


\section{GRAS PROCESS FOR INDUSTRIAL MICROBIAL ENZYMES}

humans and other animals. Enzymes are found to be ubiquitous in fresh and processed foods and have not been associated with toxicity in the human diet. ${ }^{6}$ Much like other proteins, once ingested, enzyme proteins are generally easily broken down into their constituent amino acids and cofactors that are indistinguishable from other food molecules.

The practical application of enzymes from plants, animals and microorganisms to accomplish certain reactions dates back many centuries before the nature or function of enzymes was fully understood. In ancient times, this was accomplished by the use of microorganisms used in fermentation processes to make bread, beer, cheese and wine. In the $20^{\text {th }}$ century, enzymes were isolated from living cells, leading to their wide-scale commercial application in the food and feed industry. Feed enzymes are typically added to animal feed to increase nutrient bioavailability by acting on feed components prior to or after consumption, i.e., within the gastrointestinal tract. In contrast, food processing enzymes are generally used during processing and then inactivated or removed prior to consumption. Foods made up of carbohydrates, fats, and proteins can be altered by enzymes during the processing of raw foods to finished products. A variety of commercial enzymes are available for use in food and are commonly used in baking, brewing, juice, dairy and other food processing applications. ${ }^{8,24}$ Enzymes from selected yeasts, fungi, and bacteria have a long history of safe use in food. For example, FDA in 1999 published a final rule in the Federal Register affirming that carbohydrase and protease enzyme preparations from Bacillus subtilis or Bacillus amyloliquefaciens are GRAS for use as direct food ingredients. ${ }^{25}$ These enzymes were part of a GRAS Petition (3G0016) submitted to FDA in 1973 by the the Enzyme Technical Association. The Federal Register Notice gives the background and describes the basis for the determination that several animal, plant and microbially derived enzymes are GRAS for their intended use in food.

Currently, industrial enzymes are commonly manufactured from microorganisms that are improved through natural selection, classical improvement techniques, and recombinant DNA technologies. Genetic modification of production microorganisms is practiced to improve productivity and/or adapt the microorganisms to industrial fermentation conditions. Although the production organism is genetically modified, the enzyme it produces may not be modified. However, in some cases, the enzyme protein itself has been engineered. Alteration of amino acid sequences does not typically involve changes to the catalytic site of the enzyme (and thus, the enzyme identity) but rather allows for the production of enzymes with improved characteristics, such as but not limited to thermal stability, improved enzymatic efficiency, and $\mathrm{pH}$ optimum that matches the application conditions. In these cases, protein-engineered enzymes are manufactured using the same processes and cellular machinery as wild-type enzymes, are structurally similar to the wild-type enzymes, and have changes that are well within the natural variation among wild-type enzymes, and thus have the same risk profiles.

Enzymes are typically sold as enzyme preparations and contain the desired enzyme(s), any metabolites of the production strain carried over from fermentation, and food-grade preservatives and stabilizers (liquid formulations). The safety of the production organism is the primary determinant of whether an enzyme is safe to use in food. ${ }^{10,11}$ Microorganisms used for enzyme production, whether wild-type or recombinant, are well characterized, non-toxigenic, and non-pathogenic. Pariza and Foster define a non-toxigenic organism as "one which does not produce injurious substances at levels that are detectable or demonstrably harmful under ordinary conditions of use or exposure" and a non-pathogenic organism as "one that is very unlikely to produce disease under ordinary circumstances.",

\section{Enzyme Characterization}

All enzyme proteins are based on the same 20 amino acid building blocks, arranged in different sequences. Enzyme proteins typically comprise several hundred amino acids folded in a unique three-dimensional structure, which determines properties such as catalytic activity, specificity, and stability.

The catalytic function is what categorizes a protein as an enzyme. Specific catalytic function is used to establish the enzyme class, e.g., $\alpha$-amylase or subtilisin protease. The active site region is highly conserved for each enzyme family. The nonactive site region has greater variation through natural adaptation to changing environments. Some adaptations may affect the enzyme's characteristics (e.g., temperature or $\mathrm{pH}$ optima, rate of enzyme action, salt tolerance, yield during fermentation).

"Enzymes are principally classified and named according to the reaction they catalyze. The chemical reaction catalyzed is the specific property that distinguishes one enzyme from another, and, therefore, is logical to use as the basis for classification and naming of enzymes", according to Webb. ${ }^{26}$ The commonly used system is from the International Union of Biochemistry and Molecular Biology (IUBMB), a recognized authority on enzyme nomenclature and classification. ${ }^{26}$ Each enzyme has an IUBMB record, which, in addition to the Enzyme Commission (EC) number and nomenclature defined by IUBMB, also lists a corresponding Chemical Abstract Service (CAS) number. The IUBMB has created a system whereby all enzymes are classified into six major classes, each subdivided into subclasses that are further subdivided. In general, an enzyme name includes both the substrate(s) and the reaction type.

It is the manufacturers' intent and commercially accepted practice that enzymes in commerce are produced, represented, and sold as enzyme preparations. An enzyme preparation contains the main enzyme activity for which it is characterized, as well as other enzyme side activities and metabolites produced by the production organism. The active components of enzyme preparations consist of biologically active enzyme proteins, which are sometimes conjugated with metals, carbohydrates, and/or lipids. Known molecular weights of the active enzyme components range from approximately 12 to 100 kilodaltons in mass. The enzyme preparation is formulated with other safe and suitable ingredients to help maintain enzyme activity and stability. The final formulated enzyme product is assessed for compliance with specifications established for enzyme preparations in the Food Chemicals Codex and by Food and Agriculture Organization of the United Nations (FAO)/World Health Organization (WHO) Joint Expert Committee on Food Additives (JECFA). ${ }^{27,28}$ In most cases, it is part of the established product quality specifications that the enzyme preparation does not contain viable cells of the production organism. 


\section{SEWALT ET AL.}

In general, ingestion of microbial enzymes is not likely to be of concern with regard to food allergies. ${ }^{29}$ Nevertheless, evaluation of the enzyme component should also include the consideration of its potential to cause an allergenic response upon ingestion. The model for the assessment of allergenicity is the 2009 Codex guidance published by FAO/WHO. ${ }^{30}$ It provides current methodology for assessing potential allergenicity by using a weight of evidence approach in the Annex titled Assessment of Possible Allergenicity and uses the sequence of the enzyme protein as the first step in the assessment. Further details of this methodology have been discussed by Ladics and co-authors. ${ }^{31}$

\section{Production Organism Characterization}

Enzymes can be produced from microorganisms that are improved through natural selection, classical improvement techniques, and recombinant DNA technologies. In some cases, the desired enzyme activity is found in a microorganism that is not suitable for production at a commercial scale. The genetic sequence of the enzyme can be transferred and expressed in a well-characterized production strain with a history of safe use. An evaluation of a genetically modified production organism will follow published methods and will include a description of the development of the host strain, the identification and characterization of the inserted genetic material, and the construction of the production strain. Any food or feed enzyme should be evaluated via the applicable decision tree that encompasses all of these elements. ${ }^{10,11}$

\section{SAFETY OF THE HOST STRAIN}

The host strain is generally selected or further optimized for maximum enzyme production. It serves as the expression host for recombinant DNA, with the resulting production organism carrying either additional copies of its endogenous gene or any other gene of interest. Safety of the production strain is the most important factor in evaluating the safety of an enzyme preparation. If the production strain has not been shown to be safe, then the enzyme preparation cannot be considered GRAS.

The history of many host strains is reported in scientific literature as well as evaluations by organizations such as FAO/ WHO's JECFA and the European Food Safety Authority (EFSA). One can also consult the GRAS Notice Inventories kept by the CFSAN and the CVM, as well as approvals listed in 21 CFR, and, in the case of animal feed enzymes, accepted enzymes and source organisms are found in Table 30.1 of the Association of American Feed Control Officials (AAFCO) Official Publication. ${ }^{32}$ The longer a host has been used and the more safe production organisms that have been derived from it, the stronger the presumption of safety. For example, Saccharomyces cerevisiae has a documented history of safe use in food and safe strains pertaining to Trichoderma reesei, Bacillus subtilis, Bacillus amyloliquefaciens, Bacillus licheniformis, Aspergillus niger, and Aspergillus oryzae, which have been used for decades to produce a myriad of different human and animal food enzymes. ${ }^{3,12,33-39}$

There are two basic approaches to demonstrate that the host strain is safe: (1) by ensuring that the host strain is nonpathogenic and non-toxigenic, as defined by Pariza and Foster for non-genetically engineered production strains; or (2) by establishing a safe strain lineage for expression of desired enzyme sequences by genetic engineering techniques, following the Pariza guidelines. ${ }^{4,6,8}$ A safe strain lineage can be established through repeated safety analysis when producing different enzymes using a particular host strain. When a GRAS determination is made for an enzyme from a production organism derived from a new host strain, the determination will be supported with safety data that includes new toxicological studies. A Safe Strain Lineage (SSL) may be considered established when enzyme preparations produced from at least two members of the strain lineage have been evaluated in safety studies and found to be non-toxigenic and non-pathogenic. Subsequent GRAS determinations on enzymes with a history of safe use in food/feed derived from new strains belonging to this SSL can rely on the safety data for the two enzymes used to establish the safety of the SSL. This is part of the evaluation process to determine whether new safety data is needed.

To demonstrate the lack of pathogenicity, the host strain must not cause disease in healthy humans or animals. In the case of human health, a literature search can help identify whether the host strain has caused disease in healthy individuals. In the case of animals, a literature search can be conducted, but if there is a lack of data, then animal studies using live organisms can be undertaken to show the inability to cause disease. To demonstrate that the strain is non-toxigenic, an analysis of the genome sequence can be conducted, focusing on identifying toxin genes. A lack of toxinencoding genes will support the conclusion of non-toxigenicity, but if toxin-encoding genes are found or already known for that species, then analytical studies should be performed to determine whether toxic secondary metabolites are produced under representative manufacturing conditions. If toxins are produced, then an animal study with appropriate dosage levels can show whether the level of toxins produced is a concern relative to the exposure in the intended use. If the animals in such a study exhibit no detrimental effects from the administration, then a conclusion that the strain is non-pathogenic and non-toxigenic, under the conditions of use, can be drawn.

\section{SAFETY OF THE TECHNIQUES USED TO DEVELOP THE PRODUCTION STRAIN}

Well-established classical mutagenesis, natural selection, or genetic engineering techniques can be used to modify the host. Regardless of the techniques used to modify the host, the resulting organism should be thoroughly characterized. If genetic engineering techniques are used, the safety of the inserted DNA and of the transformation techniques needs to be considered and described. The plasmid/vector should be well characterized and described. Elements required for replication, selection, and expression identified in the sequence and the plasmid used for transformation of the recipient (parent) strain should not contain genes involved in active transfer or mobilization and should be demonstrated to be non-transferable according to accepted methodologies as also defined by EPA in 40 CFR $\$ 725.421(\mathrm{c}) .{ }^{14,40,41}$ There are several commercially available plasmids that meet these requirements and have been established and documented as safe vectors. In addition, one needs to show that the inserted DNA does not encode any harmful substance or produce any unintended effects as a result of insertion into the genome. ${ }^{12}$ 


\section{GRAS PROCESS FOR INDUSTRIAL MICROBIAL ENZYMES}

The source of the enzyme gene expressed in the production organism is of interest for identification purposes and should be included in the documentation, if known. However, it is less relevant for establishing the safety of the commercial product, as long as only the gene of interest is transferred, without additional sequences that might encode harmful traits.

All inserted DNA should be well characterized. Any open reading frame (ORF) inserted or introduced should be known and characterized such that the translation start and stop sites are identified within the sequence. In addition, the inserted sequence should only contain those elements pertinent to the expression of the enzyme of choice and not include extraneous sequences unrelated to the enzyme expression. Although cloning can accomplish this if done carefully, this modification is accomplished more easily if the sequence is generated in silico such that only the coding sequence and essential expression signals are transferred to the host organism, eliminating the possibility of transferring any donor sequence other than the intended and well-characterized target enzyme sequence.

Selection markers are often used during strain construction to enable straightforward selection of colonies that have incorporated the gene. Selection markers allow only those cells that take up the desired sequences to survive during the strain selection process, so only those cells that incorporated the sequences will live and thrive. The competent cells used in transformation either are susceptible to an antibiotic (unless effectively transformed with an antibiotic resistance marker (ARM) coupled to the target gene of interest) or cannot generate a required metabolite needed to survive (unless the gene that is crucial in producing the required metabolite is included with the enzyme sequence). Therefore, only those cells that incorporated the marker genes would survive in media containing the antibiotic or lacking the required metabolite.

Removal of the ARM prior to deployment of the strain in commercial enzyme manufacture is advised. If a selection marker used during strain development is not subsequently removed, it cannot confer resistance to an antibiotic of clinical relevance to humans or animals (a current minimum regulatory requirement in various jurisdictions governing food or feed safety). In addition, the marker cannot be present on a plasmid that is easily mobilizable or transferable to wildtype species, which would make those microbes antibiotic resistant in case of inadvertent release into the environment. Regardless of the presence or absence of an ARM in the production strain, it is prohibited to use antibiotics in commercial enzyme manufacture.

\section{SAFETY OF THE PRODUCTION STRAIN}

The safety of the production strain remains the primary consideration in evaluating enzyme safety. ${ }^{9,10}$ Starting with a safe host strain, and using safe and accepted modification techniques as discussed above, all genetic modifications are expected to be well characterized and specific. The incorporated DNA should not encode and express any known harmful or toxic substances. The sequence of the introduced DNA is determined and the strain is assessed for genetic stability with regard to the introduced DNA and for the potential for transfer of genetic material..$^{40}$ The production strain is then considered safe for the production of enzymes used in food and feed.

\section{Manufacturing Process Description}

The manufacturing process follows generally available and accepted methods for the production of microbially derived enzymes. ${ }^{19-21}$ The enzyme preparations are typically produced in pure culture fermentation according to current food Good Manufacturing Practices (cGMP), using ingredients that are acceptable for use in food and under conditions that ensure a controlled fermentation. Use of aerobic submerged fermentation (SF) in a stirred-tank reactor is the typical industrial process in most situations. However, interest in Solid-Phase Fermentation (SPF) for culturing microorganisms has been renewed.

\section{SUBMERGED FERMENTATION}

Most commercially available enzymes are produced in stainless-steel, pressurized vessels of dozens and even hundreds of cubic meters of volume. Into these tanks, raw materials (safe and suitable sources of carbohydrates, proteins, and various salts) are dissolved or suspended and sterilized through a thermal process. Simultaneously, a previously laboratory-grown inoculum is aseptically added to a first vessel called the seed tank to increase the amount of the microorganism concentration. Depending on the scale of fermentation, several seed tank steps of increasing volume may be necessary. Once the seed tank fermentation is completed, the total volume is transferred to the main fermentation tank with sterile fermentation broth.

For bacterial and yeast fermentations, the length of the process ranges from 48 to 96 hours. Fungal fermentations can last $300 \mathrm{~h}$ or more, if a semi-continuous or continuous regime is used. Throughout this time, a number of parameters $(\mathrm{pH}$, oxygen, temperature, concentration of nutrients, and cells) are thoroughly managed to accomplish the highest possible production of the desired enzyme. After fermentation, the downstream process operations (recovery and formulation) are performed to reach the final commercial enzyme product.

\section{SOLID-PHASE FERMENTATION}

SPF is a process of culturing fungal microorganisms on solid materials appropriate for the species (the surface of grains, legumes, or lignocellulosic materials) with little or almost no water. ${ }^{42}$ The microorganism absorbs nutrients from the solid material and secretes the enzyme onto the surface. The same parameters as in SF are controlled throughout the process and after the fermentation is stopped, the steps to recover the enzyme from the media are essentially the same, as can be seen in Fig. 3. In this case an additional suspension step is necessary to gather as much enzyme as possible.

\section{RECOVERY AND FORMULATION}

Enzymes are recovered from the fermentation broth by chemical engineering operations broadly used in enzyme production. ${ }^{20,21}$ If the enzyme is intracellular, breakdown of the cells to release the enzyme to the broth is required. This can be done by mechanical (high-pressure press, grinding, or ultrasound) or non-mechanical drying or lysing methods. For extracellular 


\section{SEWALT ET AL.}

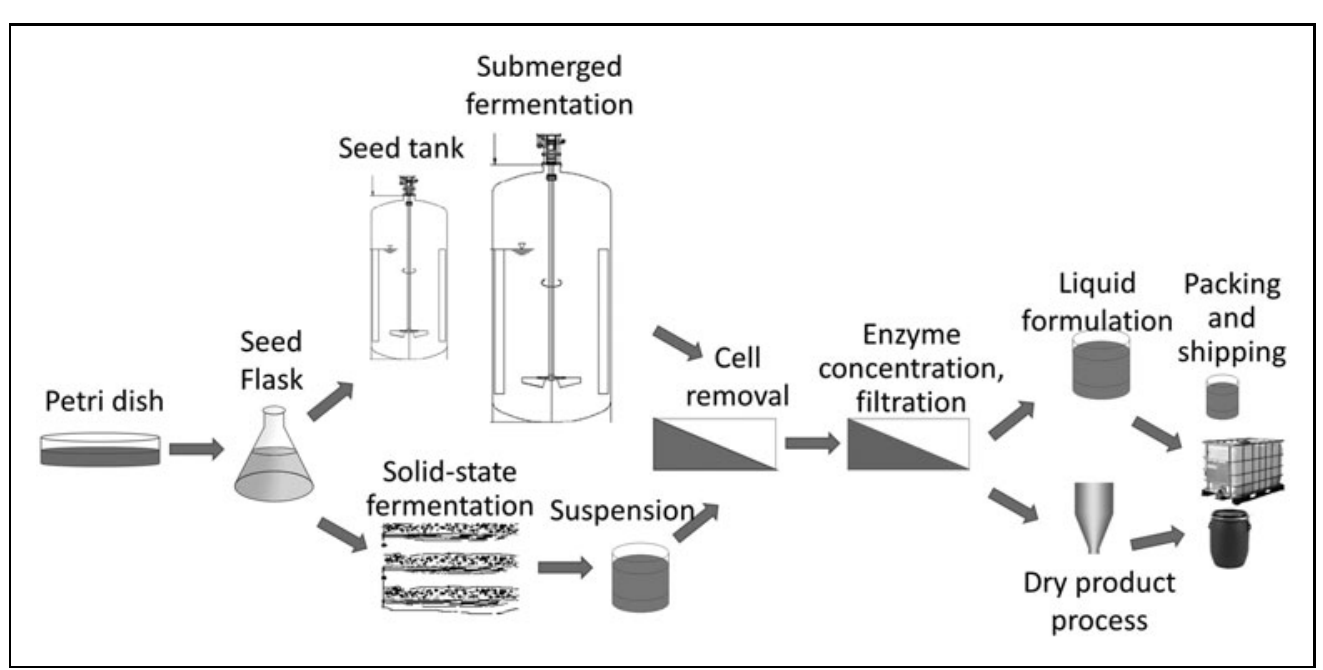

Fig. 3. General diagram for the manufacturing process of enzymes.

enzymes, a first separation step (centrifugation, filtration or both) is often used to remove the cells. Then the dissolved enzyme is concentrated by removing the water (cross-flow filtration or evaporation), resulting in an enzyme concentrate. Alternatively, a whole broth enzyme preparation (without removal of inactivated cells or cell debris) may be appropriate in select enzyme applications where the resulting food undergoes further refinement, such as potable alcohol. In all cases, the resulting enzyme preparation does not contain live production organisms.

The concentrate is then formulated with acceptable ingredients to stabilize and standardize the enzyme. Raw materials used in recovery and formulation need to be of suitable purity for the intended use and need to be used according to Good Manufacturing Practices, i.e., in the minimum amounts needed to achieve the desired effect. Use of potential allergens in the process to manufacture food enzymes needs to be addressed and, if warranted, included on the enzyme preparation. Upon completion of the manufacturing process, the final formulated enzyme product is released after testing to verify compliance with specifications for microbial and chemical contaminants established for enzyme preparations by the Food Chemicals Codex and FAO/WHO's JECFA. ${ }^{27,28}$ In most cases, it is part of the established quality specification that the enzyme preparation does not contain viable cells of the production organism.

\section{Safety Assessment}

If the enzyme protein is well characterized, the production organism has been established as a safe strain after being thoroughly characterized (as described above), and the introduced DNA and rDNA techniques used to modify the organism are well known and appropriate for food use, it is highly unlikely that the enzyme preparation will pose any safety risks. The Pariza decision tree is used to determine whether new safety studies are warranted, and FDA has accepted this approach, as documented in various GRAS Notices. ${ }^{10}$ In addition, all enzymes should be analyzed for relevant toxins/secondary metabolites that are known to be produced by the production organism or closely related species. It is important to note that under the criteria of the decision tree, no new enzyme can enter the market without critical evaluation of its safety.

\section{SAFETY STUDIES}

The need for safety studies as well as the type and length of the studies are determined on a case-bycase basis following the recommendations in the decision tree established by Pariza and Foster and later confirmed and updated by Pariza and Johnson for enzymes produced by genetically engineered microorganisms and by Pariza and Cook for protein-engineered enzymes. $^{9-11}$ The enzyme manufacturer can determine the appropriate safety studies by answering the questions in the decision trees developed by Pariza and co-authors. Even though there is no evidence that enzyme preparations display any genotoxicity, a typical toxicology program for enzymes used in food or feed includes two in vitro genotoxicity studies (Ames assay and chromosomal aberration test) in addition to a 90-day repeated dose rodent oral toxicity study to derive the No Observed Adverse Effect Level (NOAEL). If a safe strain lineage has been established, one can rely on the NOAEL from a 90-day oral toxicity study for an enzyme from a member of the lineage. ${ }^{4,6}$

The Pariza and Cook publication discusses the applicability of the food enzyme decision tree to enzymes used in animal feed. ${ }^{6,11}$ As the Enzyme Marketing Coordination document in the AAFCO Official Publication states that enzyme preparations that meet or surpass the criteria in the Pariza and Foster decision tree are safe for use in animal feed, the updated version published by Pariza and Cook becomes the authoritative source for determining the safety of animal feed enzymes. ${ }^{4,11,32}$ Pariza and Cook as well as the AAFCO Official Publication indicate that, as an alternative, one can rely on a target animal species safety study showing no adverse effects when the most sensitive class of target animal (e.g., piglets) is fed at least five times the maximum supplementation level for a period of 90 days or $50 \%$ of the species' normal growing period, whichever is less. ${ }^{11,27}$

The concept of Total Organic Solids (TOS) was developed as a means of determining the toxicological significance of enzyme test materials used in safety studies TOS is defined as the sum of the organic compounds, excluding the diluents, contained in the final enzyme preparations. ${ }^{4}$ It is derived experimentally by TOS $(\%)=$ $100-\%$ Ash $-\%$ Water $-\%$ diluents. Both the safe level derived from toxicological studies and the exposure in the intended use are to be expressed in $\mathrm{mg}$ TOS$/ \mathrm{kg}$ body weight. This reflects that the safety of the enzyme production organism is the primary consideration in evaluating the safety of an enzyme preparation. ${ }^{10,11}$

\section{EXPOSURE ASSESSMENT}

An estimation of the oral exposure to the enzyme or its inactive residue is made by using the maximum recommended 


\section{GRAS PROCESS FOR INDUSTRIAL MICROBIAL ENZYMES}

dose in the intended applications (based on TOS) and the consumption of the particular food or feed where the enzyme will be applied. The exposure is calculated in a cumulative manner summing the worst-case exposure resulting from each use. Alternatively, the Budget Method may be used to estimate total worst-case exposure via liquid and solid foods using standard maximum consumption estimates for each. ${ }^{43}$

\section{MARGIN OF SAFETY}

A safety margin can be calculated by using the dose level with NOAEL divided by the estimated human or animal oral exposure estimated using the Budget Method. There should be no adverse effect at a dose that is 100 times the estimated mean human exposure, based on TOS. This is based on the traditional 100-fold safety factor applied to food ingredients by FDA and published evaluation methodology. ${ }^{4,5,22}$

\section{Conclusion}

The GRAS concept is particularly well suited for enzymes for a number of reasons. Enzymes have a long history of safe use in food processing and animal feed. Microbial enzymes are produced under contained conditions following generally available and accepted methods. The majority of enzymes are produced by microorganisms that are routinely used for the manufacture of enzymes and other food ingredients and that pertain to safe strain lineages. Repeated evaluation of enzymes from the same production organism pertaining to the same lineage has resulted in the establishment of multiple safe strain lineages. Enzymes from a production organism that does not pertain to a safe strain lineage are tested in toxicological studies that address genotoxicity and repeated-dose oral toxicity in rodents. The lack of any adverse effect in the plethora of oral toxicity and genotoxicity safety studies, both published and unpublished, supports the suitability of enzymes for use in food processing and in animal feed.

When enzymes from safe and suitable production organisms are intended for inclusion in the feed of production animals, human food safety is generally not of concern, as humans consuming products from the target animal are generally not exposed to the enzymes. As enzyme proteins are generally digestible, there is little to no potential for residues in the edible animal tissue. In addition, enzymes used in final feed product formulas are manufactured to adhere to the same strict specifications for metal and microbial contaminants as food enzymes, and thus these contaminant residues will not accumulate in meat, milk, or eggs beyond what is typically found in those products. Similarly, environmental fate is of little concern for enzymes given their degradation to amino acids. The lack of human exposure to enzymes in animal products from animals consuming the enzymes in their feed and lack of environmental concerns further support the suitability of animal feed enzymes to the GRAS process, which, contrary to the Food Additive Petition Process, does not trigger a formal requirement to address environmental fate and human food safety.

The safety of enzymes used in food and feed is further supported by well-established and recognized safety evaluation procedures that include a decision tree designed for both naturally selected and genetically modified production strains. The latter emphasizes safe transformation methods and thorough charac- terization of the inserted DNA. Together, the published and unpublished data and information available on the safety of the enzyme, manufacturing process, production organism, toxicity studies, and safety evaluation provide the basis for a determination of GRAS, which qualifies the enzyme for the GRAS process and exemption from premarket approval as a food additive.

In the process of evaluating hundreds of enzyme preparations in commerce, a number of GRAS notices have been filed (Fig. 1). The majority have published safety data specifically on that enzyme or published literature on the species of the production organism. A body of safety data in support of enzymes has been developed. In addition, for animal feed enzymes, published safety studies and a long history of safe use demonstrate that there are no environmental or human food safety concerns.

\section{Acknowledgments}

The authors thank members of the Enzyme Technical Association (Candice Cryne, Tichafa Munyikwa, Kumiko Paik, Scott Krygier, Richard Jundzil, Emily Helmes, and Roxanna Van Dorn), as well as Kees Broekhuizen and Peter Hvass for input and critical review of this paper.

\section{Author Disclosure Statement}

No competing financial interests exist.

\section{REFERENCES}

1. 21 U.S.C. § 321 Definitions; generally. In: United States Code, 2006 Edition, Supplement 4, Title 21 Food and Drugs. 33-34. US Government Publishing Office (GPO), 2010. Available at www.gpo.gov/fdsys/pkg/USCODE-2010-title21/pdf/ USCODE-2010-title21-chap9-subchapll-sec321.pdf (Last accessed May 2016).

2. 21 CFR $§ 182$ Direct food substances generally recognized as safe. In: Code of Federal Regulations Title 21, Subchapter B-Food For Human Consumption: 472-485. Office of the Federal Register National Archives and Records Administration (NARA)/US Government Puplishing Office (GPO), 2015, Washington, DC. Available at www.gpo.gov/fdsys/pkg/CFR-2015-title21-vol3/ pdf/CFR-2015-title21-vol3-part182.pdf (Last accessed May 2016).

3. 21 CFR $\$ 170.35$ Affirmation of generally recognized as safe (GRAS) status. In: Code of Federal Regulations Title 21, Subchapter B-Food For Human Consumption, Part 170-Food Additives, Subpart B-Food Additive Safety, Section 35: 15-17. Office of the Federal Register National Archives and Records Administration (NARA)/US Government Puplishing Office (GPO), 2015, Washington, DC. Available at www.gpo.gov/fdsys/pkg/CFR-2015-title21-vol3/ pdf/CFR-2015-title21-vol3-sec170-35.pdf (Last accessed May 2016).

4. US Food and Drug Administration. Substances Generally Recognized as Safe, Proposed Rule. Fed Reg 1997;62(74):18938-964. Available at https:// federalregister.gov/a/97-9706 (Last accessed May 2016).

5. US Food and Drug Administration. Generally Recognized as Safe (GRAS) Available at www.fda.gov/Food/IngredientsPackagingLabeling/GRAS/ (Last accessed September 2016).

6. US Food and Drug Administration. Substances Generally Recognized as Safe added to food for animals; Notice of Pilot Program. Fed Reg 2010;75(107):31800-31803. Available at https://federalregister.gov/a/201013464 (Last accessed May 2016).

7. US Food and Drug Administration. Generally Recognized as Safe (GRAS) Notification Program. Available at www.fda.gov/AnimalVeterinary/Products/ AnimalFoodFeeds/GenerallyRecognizedasSafeGRASNotifications/default.htm (Last accessed September 2016).

8. Olempska-Beer ZS, Merker RI, Ditto MD, DiNovi MJ. Food-processing enzymes from recombinant microorganisms-A review. Regul Toxicol Pharmacol 2006;45(2):144-158. 


\section{SEWALT ET AL.}

9. Pariza MW, Foster EM. Determining the safety of enzymes used in food processing. J Food Prot 1983;46(5):453-468.

10. Pariza MW, Johnson EA. Evaluating the safety of microbial enzyme preparations used in food processing: Update for a new century. Regul Toxicol Pharmacol 2001;33(2):173-186.

11. Pariza MW, Cook M. Determining the safety of enzymes used in animal feed Regul Toxicol Pharmacol 2010;56(3):332-342.

12. International Food Biotechnology Council. Safety evaluation of foods and food ingredients derived from microorganisms. Regul Toxicol Pharmacol 1990;12(3):S114-S128.

13. EU Scientific Committee for Food. Guidelines for the presentation of data on food enzymes. Reports of the Scientific Committee for Food, 27th series (1991) Available at http://ec.europa.eu/food/fs/sc/scf/reports/scf_reports_27.pdf (Last accessed September 2016).

14. Organisation for Economic Cooperation and Development. Safety Evaluation of Foods Derived by Modern Biotechnology. Concepts and Principles (1993). Available at www.oecd.org/science/biotrack/41036698.pdf (Last accessed April 2016).

15. Berkowitz D, Maryanski J. Implications of biotechnology on international food standards and codes of practice. Joint FAO/WHO Food Standards Programme, Codex Alimentarius Commission, 18th Session, Geneva, July 3-12, 1989.

16. FAO/WHO. Biotechnology and Food Safety, Report of a Joint FAO/WHO Consultation. FAO Food and Nutrition Paper 61. Rome, Italy, 1996.

17. Jonas DA, Antignac E, Antoine JM, et al. The safety assessment of novel foods Guidelines prepared by ILSI Europe Novel Food Task Force. Food Chem Toxicol 1996;34(10):931-940.

18. European Food Safety Authority. Guidance of the Scientific Panel of Food Contact Material, Enzymes, Flavourings and Processing Aids (CEF) on the Submission of a Dossier on Food Enzymes for Safety Evaluation (2013). Available at: www.efsa.europa.eu/en/efsajournal/pub/1305 (Last accessed April 2016).

19. Kroschwitz, Jl. Enzyme Applications. In: Kroschwitz Jl, ed. Encyclopedia of Chemical Technology, 4th Ed. 1994;(9)567-620.

20. Aunstrup, K. Production, Isolation, and Economics of Extracellular Enzymes. In: Wingard LB, Katchalski-Katzir E, Goldstein L eds. Applied Biochemistry and Bioengineering Vol 2, Enzyme Technology. 1979:28-68.

21. Aunstrup, $K$, Andersen 0 , Falch EA, Nielsen TK. Production of Microbial Enzymes. In: Peppler HJ, Perlman D, eds. Microbial Technology 2nd Ed. 1979(1): 282-309.

22. 21 CFR $\oint 170.22$ Safety factors to be considered. In: Code of Federal Regulations Title 21, Subchapter B-Food For Human Consumption, Part 170-Food Additives, Subpart B-Food Additive Safety, Section 22:13-15. Office of the Federal Register National Archives and Records Administration (NARA)/US Government Puplishing Office (GPO), 2015, Washington, DC. Available at www.gpo.gov/fdsys/pkg/CFR-2011-title21-vol3/pdf/CFR-2011-title21-vol3sec170-22.pdf (Last accessed April 2016).

23. CFSAN. Enzyme Preparations: Recommendations for submission of chemical and technological data for food additive petitions and GRAS Notices. Guidance for Industry (2010). Available at www.fda.gov/downloads/Food/ GuidanceRegulation/UCM217735.pdf (Last accessed May 2016).

24. Association of Manufacturers and Formulators of Enzyme Products. AMFEP List of commercial enzymes (2015). Available at www.amfep.org/sites/g/files/ g412356/f/201505/Amfep\%20List\%20of\%20Enzymes\%20update\%20May\%20 2015.pdf (Last accessed April 2016).

25. US Food and Drug Administration. Carbohydrase and protease enzyme preparations derived from Bacillus subtilis or Bacillus amyloliquefaciens; Affirmation of GRAS Status as direct food ingredients. Fed Reg 1999;64(78):19887-18895. Available at https://federalregister.gov/a/99-10011 (Last accessed May 2016).

26. Webb EC. Enzyme Nomenclature (2016). Available at: www.chem.qmul.ac.uk/ iubmb/enzyme/ (Last accessed April 2016).

27. US Pharmacopeia.Monograph: Enzyme preparations. In: Food Chemicals Codex, 10th Ed. The United States Pharmacopeial Convention, Rockville, Maryland. 2016:445-450.
28. Joint FAO/WHO Evaluation Committee for Food Additives (JECFA). Genera specifications and considerations for enzyme preparations used in food processing. In: Compendium of food additive specifications, volume 4 . Analytical methods, test procedures and laboratory solutions used by and referenced in the food additive specifications. FAO/JECFA Monographs 1. Rome, Italy. 2006:xxi-xxV.

29. Bindslev-Jensen C, Skov PS, Roggen EL, et al. Investigation on possible allergenicity of 19 different commercial enzymes used in the food industry. Food Chem Toxicol 2006;44(11):1909-1915.

30. Codex. Guideline for the Conduct of Food Safety Assessment of Foods produced using Recombinant-DNA Micro-Organisms. In: FAO/WHO. Food derived from modern biotechnology (2009). Available at ftp://ftp.fao.org/codex/Publications/ Booklets/Biotech/Biotech_2009e.pdf (Last accessed September 2016).

31. Ladics GS, Cressman FR, Herouet-Guicheney $C_{\text {, et }}$ al. Bioinformatics and the allergy assessment of agricultural biotechnology products: Industry practices and recommendations. Regul Toxicol Pharmacol 2011;60(1):46-53.

32. American Association of Feed Control Officials (AAFCO). Enzyme Marketing Coordination (Section Editor: Mika Alewynse). In: AAFCO Official Publication, 2015:328-334.

33. Nevalainen $H$, Suominen $P$, Taimisto $K$. On the safety of Trichoderma reesei. J Biotechnol 1994;37(3):193-200.

34. Blumenthal CZ. Production of toxic metabolites in Aspergillus niger, Aspergillus oryzae, and Trichoderma reesei: Justification of mycotoxin testing in food grade enzyme preparations derived from the three fungi. Regul Toxicol Pharmacol 2004;39(2):214-228.

35. de Boer AS, Diderichsen B. On the safety of Bacillus subtilis and B. Amyloliquefaciens: A review. Appl Microbiol Biotechnol 1991;36(1):1-4.

36. de Boer AS, Priest F, Diderichsen B. On the industrial use of Bacillus licheniformis-A review. Appl Microbiol Biotechnol 1994;40(5):595-598.

37. Schuster E, Dunn-Coleman N, Frisvad JC, Van Dijck PWM. On the safety of Aspergillus niger-A review. Appl Microbiol Biotechnol 2002;59(4):426-435.

38. Van Dijck PWM, Selten CGM, Hempenius RA. On the safety of a new generation of DSM Aspergillus niger enzyme production strains. Regul Toxicol Pharmacol 2003;38(1):27-35

39. Barbesgaard P, Heldt-Hansen HP, B Diderichsen. On the safety of Aspergillus oryzae. Appl Microbiol Biotechnol 1992;36(5):569-572.

40. National Institutes of Health (NIH). Guidelines for Research Involving Recombinant or Synthetic DNA Molecules, Appendix I (2016). Available at http:// osp.od.nih.gov/sites/default/files/NIH_Guidelines_0.pdf (Last accessed April 2016).

41. 40 CFR $\$ 725.421$ Introduced genetic material. In: Code of Federal Regulations Title 40, Part 725 Reporting Requirements and Review Processes for Microorganisms: 838-840. Office of the Federal Register National Archives and Records Administration (NARA)/US Government Puplishing Office (GPO), 2015, Washington, DC. Available at www.gpo.gov/fdsys/pkg/CFR-2015-title40-vol31/ pdf/CFR-2015-title40-vol31-sec725-421.pdf (Last accessed May 2016).

42. Baltz RH, Davies JE, Demain, AL. Solid-phase fermentation: Aerobic and anaerobic. Manual of Industrial Microbiology and Biotechnology, 3rd Ed. ASM Press, Washington, DC 2010;117-131.

43. Douglass JS, Barraj LM, Tennant DR, et al. Evaluation of the budget method for screening food additive intakes. Food Addit Contam 1997;14(8):791-802.

Address correspondence to:

Vincent J.H. Sewalt, PhD

Senior Director, Product Stewardship \& Regulatory

DuPont Industrial Biosciences 925 Page Mill Road Palo Alto, CA 94303 Phone: (650) 8465861

E-mail: vincent.sewalt@dupont.com 